\title{
A TRACKING STUDY WHEN DETRENING AT THE LEVEL OF SCORING FOR PROFESSIONAL PLAYERS BASKETBALL
}

\author{
Ahmed Taha Salim, Prof.Dr. Wasan Hnoon Ali \\ University of Baghdad / College of Physical Education and Sports Sciences
}

DOI: $10.37648 /$ ijrssh.v10i02.026

Received: $30^{\text {th }}$ March, 2020; Accepted: $20^{\text {th }}$ April, 2020; Published: $13^{\text {th }}$ May,2020

\begin{abstract}
The aims of the study was to reach scientific results through a follow-up study when there was a detraining at the skill level (Complex offensive skill) during an eight-week period of detraining for basketball players for professinall by taking a shooting skill test And score three points from receiving and jumping, and the researcher used the experimental method, A sample of Baghdad players for 15 basketball Professional for the season (2018-2019). The first test was taken immediately after the end of the league, and the second test was taken after the first test (4 weeks). The third test was conducted after the second test with (4 weeks), meaning that the period of detraining was (8 weeks), The data was collected and treated using proper statistical operations to conclude the following: The detraining had a negative impact on the level of speed and accuracy of the skill, there is a decline in the level of performance in complex offensive skill, There is a decline in the level of performance in the offensive complex skill under discussion, which is the correction of receiving and jumping shooting by three points.
\end{abstract}

\section{INTRODUCTION}

The tremendous progress made and observed in the sports field at various levels, which has achieved a great qualitative leap and great achievements in sports and that today we need to make more scientific training effort to develop sports skills in all activities, especially basketball, which is the subject of research, that the process of upgrading to higher levels And obtaining an achievement that does not come by chance or by random methods, but there are foundations for the totality of these operations, and the basketball game is one of the difference games that need skill and planning requirements, as indicated by (Muhammad Abdul Rahib Ismail 2003) to "(the individual's ability to perform the movement group" Special $t$ contained accurately and the adequacy of the game and success) at a high level. " And it becomes effective in the results of matches that require a high level of accuracy and speed in scoring, as (Firas Mutasher Abdul Reda 2010) indicated, "To receive and jump high and aiming with three points of the important skills as they play from ten players in small spaces sometimes, so they require from The player has fast kinetic behavior and sophisticated scoring according to changing situations, basketball is a game that requires high physical fitness in addition to mastery of skill and tactical performance as it requires a high level of speed, strength and durability ", indicated by both Kraus Jerry and Nelson Kreus Jerry V., Nelson, Craig2012) "Basketball is one of the fast games, and passing and aiming skills from jumping are among the most important skills to be mastered to achieve positive results. In the attack in order to achieve its goals, "and one of the important skills is to shoot from the wilderness with three points," (Nada Mahfouz Abdel Azim Kabuh 2007) indicated that "it became difficult to keep training and straightening basic skills separate separately ... and it is 
necessary to use complex offensive skills during matches." As one of the means Important in overcoming the modern defensive ways. (Ali Mohsen Ali 2014) stated that "since the skill (the art of kinetic performance) in any of the sports games and aiming or scoring with three points from receiving and jumping is one of the types of correction desired by the players and it is one of the difficult corrections that need a good physical preparation As the muscles of the two men are characterized by the strength marked by speed, it can be performed from all sides of the field and jumping over the hands of the high defense high.

As for the discontinuation of training, I knew Mujika and Padilla (2002), which is the temporary discontinuation of organized physical training aimed at developing the elements of physical fitness, and at the same time it is necessary to maintain it, which often occurs after the end of the sports season and before the start of the new season or Upon injury or due to illness, which also requires compulsory clinical rest in some cases "as indicated (AlHazaa Bin Muhammad Al-Hazaa 2007)" in the event of discontinuation of physical training occurring after the end of the sports season in the absence of a compensation program during the stopping period to maintain physical fitness players It must be e AAC long enough numbers ranging from 8 weeks to 10 weeks and this period may help to regain fitness and reduce the chances of injury that you get a result of intense preparation before the start of the new season."

This is what attracted the attention of the researchers, and after that, I started the idea of doing a study through which a solution to this problem contributes to interruption and what can be lost from the skill side in the accuracy of scoring

From here the goal of the research appeared in obtaining scientific results through a follow-up study at a break from training in the skill level (complex skill) during an eightweek period of discontinuance for basketball players for applicants by conducting a correction skill test calculated with three points of receipt and jump, which During which to find the appropriate solution according to the foundations of scientific research.
With regard to studies related to the skill level and discontinuation of training: In a study conducted by Santos, Eduard JAM 2015 (Janeia 2015) on first-degree players in the Portuguese League after intense training for 14 days on scoring from jumping after receiving the ball and training on The explosive strength of the arms and the interruption of training and the interruption of training for 10 days on a sample of 16 players. The study sample consisted of (20) players with the design of one group, and the group was subjected to the pre and post measurements. In the results of this In three points after receiving the ball and jump, and did not statistically significant differences observed in the explosive capacity.

)Kibler WB, McQueen C 2018) indicated during a study conducted on basketball players from Ohio University, the sample consisted of 22 players with a one-group system and pre and post testing and were given flexible exercises for the shoulder and elbow with scoring from the threepoint area for 14 days and then stop training 14 days and his program focused on flexibility. Improving the movement of the rotation of the internal and external shoulder and scoring from outside the three-point arc because he believed the most movements used by the basketball player, and that the lack of flexibility of the shoulder is a factor that helps in accurate scoring. Precision In scoring from outside the three-point area when you statistically drop out.

\section{MATERIALS AND METHODS:}

The researcher used the descriptive approach with one group in a traceable way using repeated tests, as it is more appropriate to solve the research problem, and the research community, represented by the premier league basketball teams for the applicants and for the season (2018-2019), was chosen from the Baghdad clubs participating in the Premier League championship matches (63) players As for the total of the sample that committed and was discontinued from the training, their number was (15) players, i.e. what corresponds to a rate of $(23.07 \%)$ from the community of the parent sample, but the specification of the sample is as shown in table (1). 
Table (1)

Statistical description of the research sample in the variables (length, time age, mass)

\begin{tabular}{|l|l|l|l|l|l|}
\hline $\begin{array}{l}\text { Coefficient of } \\
\text { torsion }\end{array}$ & $\begin{array}{l}\text { standard } \\
\text { deviation }\end{array}$ & Mediator & $\begin{array}{l}\text { The arithmetic } \\
\text { mean }\end{array}$ & $\begin{array}{l}\text { measruing } \\
\text { unit }\end{array}$ & Variables \\
\hline 0.948 & 14.106 & 84.000 & 87.800 & Kg & the weight \\
\hline 0.316 & 8.228 & 187.000 & 189.533 & $\mathrm{~cm}$ & Length \\
\hline-0.150 & 2.475 & 23.000 & 22.867 & Year & Age \\
\hline 0.509 & 2.455 & 24.020 & 24.317 & Kg / m2 & body mass \\
\hline
\end{tabular}

The researchers used the means by which to solve the research problem and reach the required results (personal interviews, Arab and foreign sources, tests and measurements, the Internet check).

As for the tools, a video camera, number (1), for authenticating Sony type, with a speed of 300 pictures per second + a stand, a scale of Seca Scala, a Samsung type device (Note 5), number (2), a fox whistle (FOX) number (2), and basket balls. Molten number (3), color tape (6), tape measure length (5 meters), number (2), stopwatch type.

\section{Exploration Experience:}

The researchers conducted the exploratory experiment on 12/12/2018 in the closed People's Hall for Sports Games on a sample of Adhamiya Basketball Club players for applicants to find out the time required for the experiment and the definition of the research sample How to perform a test and the time required to perform and how to calculate accuracy according to the Fits law.

\section{Main experience:}

The first main experiment: The researchers conducted the main experiment procedures in the closed Hall of the People for sports games on (9/3/2019), at (5 pm) starting with taking the sample weight and length to extract the mass, generation to know age, extract the mass (BMI) through the equation.

Mass $(\mathrm{BMI})=$ weight $(\mathrm{kg}) /($ length $(\mathrm{m})) 2$

Combined offensive skill test ending with three-point correction calculated as indicated by (Hamid Ahmed Mohamed 2018)

- The purpose of the test: to measure the level of performance for the correction of the calculated jump by three points.
- The necessary tools: a basketball court, one barrier, (3) legal basketball balls, a leather tape measure (20) meters, adhesive tape, an electronic stopwatch, two chairs, and a whistle.

- Procedures: The starting point is set in front of the arc of the central circle in the middle of the stadium, in which the laboratory player leading to aiming stands and is 7 meters away from the side line and a distance of 11 meters from the final line, then a central point is set at the bottom of the basket that depends on marking some key points, see Figure (3) determines the location of the first area on the (right) side of the target, at a distance of (7) $\mathrm{m}$ from the center of the point at the bottom of the basket and away from the side line of the stadium $(3,80) \mathrm{m}$. The defensive player along the imaginary line between the aiming player and the basket, then locates the area.

- The second is on the right side of the goal and is $(0,90) \mathrm{m}$ from the stadium's side line and a distance of (2) $\mathrm{m}$ from the final stadium line, which represents the player's standing stance.

- Performance description: The handled player stands on the first left side point pointing to the ground, and at the same time he carries the ball with him and at the start signal the ball is delivered by a ball launcher or (chesthanded handling) from the handled player to the laboratory player who performs the receipt ending with correction and jumping (Three points) directly, as shown in steps (1) and (2) and (3), and the player performs the test (3) attempts, as in Figure (2).

- Test conditions: speed in performance, and assisting the laboratory player (alert) to perform attempts from its specified location by a member of the work team standing on the front point by handing (3) balls each ball separately according to the performance description.

Test administration:

Timer: It gives the starting signal as well as calculating the time taken to perform for each attempt and individually for each correction from the moment of receipt to the moment 
the ball leaves the hand of the player and if there is a camera of a certain speed can be replaced by the work of the timer, which is more accurate in calculating time.

Registered: performs the call on names first and marks both successful and failed attempts and time second.

Grade Account:

The time is calculated when the tested player receives the ball until the end of the attempt, except that the ball leaves the player's hand.

Score: The outcome of the attempt's accuracy divided by its time and according to the Fits Law.

Degree: the division of the outcome of the attempted accuracy over its time.

)4 (A score for the ball directly into the basket -

)3 (The degree of the inside ball by touching the throat -

) 2 (For the entering ball by touching the board -

)1 (degree when it touches the throat or plate and does not enter the basket -

Table (2)

Calculate the mean and deviation of the scoring tests calculated by three points

\begin{tabular}{|c|c|c|c|c|c|c|c|c|c|}
\hline Sig. & $\mathrm{F}$ & $\begin{array}{l}\text { Middle } \\
\text { square }\end{array}$ & df & $\begin{array}{l}\text { Sum of } \\
\text { squares }\end{array}$ & $\begin{array}{l}\text { Between } \\
\text { and within } \\
\text { groups }\end{array}$ & $\begin{array}{l}\text { standard } \\
\text { deviation }\end{array}$ & $\begin{array}{l}\text { Arithmetic } \\
\text { mean }\end{array}$ & the test & Skill \\
\hline \multirow{4}{*}{.000} & \multirow{4}{*}{120.00} & 5.67 & 2 & 11.33 & $\begin{array}{l}\text { Between } \\
\text { the totals }\end{array}$ & 0.20 & 2.06 & Test 1 & \multirow{4}{*}{$\begin{array}{l}\text { Scoring level } \\
(\mathrm{P} 3) / \\
\text { Minutes } \\
\text { second }\end{array}$} \\
\hline & & & 42 & 1.98 & $\begin{array}{l}\text { Inside the } \\
\text { totals }\end{array}$ & 0.26 & 1.29 & Test 2 & \\
\hline & & 0.05 & 44 & 133 & Total & 0.19 & 0.85 & Test 3 & \\
\hline & & & & & & 0.55 & 1.40 & Total & \\
\hline
\end{tabular}

Significant at $(\mathrm{Sig})<(0.05)$

Table (3)

LSD assessed scoring tests with three points

\begin{tabular}{|l|l|l|l|l|l|}
\hline Moral in favor of & Sig. & A- e & Q- F. & the exams \\
\hline Test 1 & $\mathbf{. 0 0 0}$ & $\mathbf{. 0 7 9}$ & $\mathbf{. 7 7} *$ & Test 1 \\
\hline Test 1 & $\mathbf{. 0 0 0}$ & $\mathbf{. 0 7 9}$ & $\mathbf{1 . 2 2} *$ & Test 3 \\
\hline Test 2 & $\mathbf{. 0 0 0}$ & $\mathbf{. 0 7 9}$ & $\mathbf{. 4 5 *}$ & Test 3 & Test 1 \\
\hline
\end{tabular}

Significant at $(\mathrm{Sig})<(0.05)$
(Zero) except that -

The second presidential experience: - The second test was conducted after (4 weeks) from the first main experiment on () and at $(5 \mathrm{pm})$ in the closed hall of the people for the games, since the test was taken after warming up for ten minutes and then the test was the complex attacking skill ending with correction Calculated by three points and by the same procedures in the first main experiment.

\section{RESULT AND DISCUSSION:}

The third main experiment: - The third test was conducted after (4 weeks) from the second main experiment and with the same procedures for testing in the previous experiments and with a date at $(5 \mathrm{pm})$ and in the closed hall of the people for sports. 
Through the results, we note that there are significant differences between the first and the second test when interrupting training for a period of (4 weeks) as (Ismail Qassem Jameel 2012) indicated that this indicates that accuracy develops as a result of training and then an increase in experience and thus in turn is reflected in performance in general and accuracy In particular, the scoring skill should be repeated as quickly as possible, focusing on accurate aiming and merging the main skill with the combined skill in order to excel in hitting the target.

As for discussing the results between the second and third tests when interrupting for another (4 weeks), we notice that there is a difference in circles that led to a decline in the level of accuracy and speed in scoring in favor of the second test, as it indicated (Abdullah 2001 meeting) that "regular training with the ball with repetition of the skill brings the player to An advanced stage in accuracy and performance, so special qualitative exercises enable to achieve what is required to be performed and that the priority is to achieve accuracy and that the basketball game is one of the games that contains a number of complex skills that mix (receiving the ball and scoring from jumping, chivalry and handling), and other skills Which T. Be the player to master the vehicle from jumping skills Kalthdev therefore requires a teacher or coach to follow a particular style of training and repetitions on each play and scoring positions quickly and accurately target the mechanism of injury"

As for discussing and comparing the results obtained when the training was interrupted for ( 8 weeks) between the first and the third tests, there is a marked decrease in the level of accuracy and speed significantly, in order to move the players away from the systematic training that affected the level of accuracy and speed and indicated (Abdullah 2001 meeting) that "offensive skills" The vehicle consists of linking or combining two or more skills that are performed in a complex form (performed as if it is one skill), and it requires players to spend more time and effort when performing more than individual skills, including receipt, prowess, scoring, and many others. ) "To increase the accuracy of the shot The following equation must be known: elaborate correction $=$ correct technical performance + repetition (the presence and absence of a defender with diversification in correction) + throwing performance in the conditions of the match, as well as the place of receiving the appropriate ball and confirmation of making the correct decision about the time of correction, and the correct height (Departure angle), correct track, and aiming at the appropriate distance"

The researcher believes that all of these things combined were a reason for the low level of accuracy and speed in scoring from jumping when receiving the ball and is counted with three points because the offensive complex skills consist of linking or combining two or more skills that are performed in a composite (performed as if it is one skill) and that discontinuation of training led The weak ability of the players to link the offensive skills with the required accuracy and speed, which increases the errors in performance to keep them away from repeat performance, this technique.

\section{CONCLUSIONS:}

- that dropping out of the trainer had a negative impact on the level of speed and accuracy of the skill.

- There is a decline in the level of performance in the complex attack skill under discussion, which is the correction of receiving and jumping calculated by three points when interruption of training for (8 weeks).

\section{REFERENCES:}

- Mohamed Abdel-Rahim Ismail (2003): - The basics of skill and offensive planning in basketball, 2nd floor, Alexandria, facility knowledge.

- Firas Mutasher Abd Al-Ridha (2010): - The effect of palliative exercises left in some of the non-oxygenic and offensive skills installed in basketball at the age of 18 years, published research, faculty of physical education, October issue (27).

- Lazim Muhammad Abbas, Qasim Muhammad Abbas (2012): - The relationship of physical abilities for skill performance according to the different playing centers of the basketball players, Qadissiya Magazine, Al-Dibriya, Al-Dibriyya Magazine, 12, Al-Dibiyah 1, Al-Dibiyah Magazine, 2012.

- Nada Mahfouz Abdel-Azim Kaboh (2007): - Setting the standard levels for some offensive complex skills tests for basketball players, Journal of the Faculty of Physical Education, Volume No. 40 Issue No. (76) dated 12/1/2007. 
- Ali Mohsen Ali (2014): - Using various weights to develop the explosive power of working muscles and their effect on the accuracy of correction of basketball for young people, Master Thesis, Al-Mustansiriya University, Basic Education.

- Mostafa Zidan, Gamal Ramadan (2008): - Teaching basketball budding, Cairo, Al-Azhar University Press.

- Al-Hazza Bin Mohammed Al-Hazza (2007): - Physiological effects of stopping physical training for 8 weeks among distinguished football players, Saudi Arabia, Riyadh, King Saud University, published research.

- Hamid Ahmed Mohamed (2018): - Relationship of some biomechanical variables and sensory capabilities - kinetic to the level of performance of some complex offensive skills ending with basketball shooting for applicants, $\mathrm{PhD}$ thesis, College of Physical Education and Sports Science, University of Baghdad.

- Ismail Qassem Jameel (2012): - The effect of special exercises using devices and tools to develop the speed of the kinetic response and the accuracy of handling and scoring for football halls players, published doctoral thesis, College of Sports Sports and Sports Sciences.

- Abdullah meeting (2001): - A suggested training curriculum to develop transitional speed in the performance of some offensive skills installed in basketball, published Master Thesis, College of Physical Education, University of Baghdad.

- Fares Sami Yusef Shaba Ska (2006): - Building and legalizing a test battery to measure some offensive skills installed in basketball for youth, published doctoral dissertation, College of Physical Education, University of Baghdad.

- Krause, Jerry V., Nelson, Craig(2012) :- Basketball Skills \& Drills-4th Edition, - books.

Mujika and،- Padilla (2002):- Detraing loss of training physiologyal and performance adaptations. ‘part 1، sport med . 